This document is confidential and is proprietary to the American Chemical Society and its authors. Do not copy or disclose without written permission. If you have received this item in error, notify the sender and delete all copies.

\section{Hybrid Integrated Photomedical Devices for Wearable Vital Sign Tracking}

\begin{tabular}{|c|c|}
\hline Journal: & ACS Sensors \\
\hline Manuscript ID & se-2019-025294.R2 \\
\hline Manuscript Type: & Article \\
\hline $\begin{array}{r}\text { Date Submitted by the } \\
\text { Author: }\end{array}$ & 29-Mar-2020 \\
\hline Complete List of Authors: & $\begin{array}{l}\text { Bae, Sang-Hoon; University of California Los Angeles, Materials Science } \\
\text { and Engineering } \\
\text { Kim, Donghyuk; University of California Los Angeles } \\
\text { Chang, Sheng-Yung; University of California Los Angeles } \\
\text { Hur, Janet; University of California Los Angeles, Department of Materials } \\
\text { Science and Engineering } \\
\text { Kim, Hyunseok; University of California Los Angeles, } \\
\text { Lee, Jin-Wook; Sung Kyun Kwan University, SKKU Advanced Institute of } \\
\text { Nanotechnology (SAINT) and Department of Nanoengineering } \\
\text { Zhu, Bowen; University of California Los Angeles, Department of } \\
\text { Materials Science and Engineering } \\
\text { Han, Tae-Hee; University of California Los Angeles, Department of } \\
\text { Materials Science and Engineering } \\
\text { Choi, Chanyeol; University of California Los Angeles } \\
\text { Huffaker, Diana; University of California Los Angeles, Electrical } \\
\text { Engineering } \\
\text { Di Carlo, Dino; University of California Los Angeles, } \\
\text { Yang, Yang; University of California Los Angeles, Materials Science and } \\
\text { Engineering } \\
\text { Rim, You Seung; Sejong University, School of Intelligent Mechatronic } \\
\text { Engineering }\end{array}$ \\
\hline
\end{tabular}

\section{SCHOLARONE" Manuscripts}




\section{Hybrid Integrated Photomedical Devices for Wearable}

\section{Vital Sign Tracking}

Sang-Hoon Bae ${ }^{\mathrm{a} \ddagger}$, Donghyuk Kim ${ }^{\mathrm{b} \ddagger}$, Sheng-Yung Chang ${ }^{\mathrm{a}}$, Janet Hur ${ }^{\mathrm{a}}$, Hyunseok Kim ${ }^{\mathrm{c}}$, Jin-Wook Lee $^{\mathrm{a}, \mathrm{d}}$, Bowen Zhu ${ }^{\mathrm{a}}$, Tae-Hee Han ${ }^{\mathrm{a}, \mathrm{e}}$, Chanyeol Choi ${ }^{\mathrm{c}}$, Diana. L. Huffaker ${ }^{\mathrm{c}}$, Dino Di Carlo ${ }^{\mathrm{b}}$, Yang Yang $^{\mathrm{a} *}$, You Seung Rim ${ }^{\mathrm{a}, \mathrm{f} *}$

a Department of Materials Science and Engineering, University of California, Los Angeles, Los Angeles, California 90095, United States

${ }^{b}$ Department of Bioengineering, University of California Los Angeles, Los Angeles, California 90095, United States

${ }^{\mathrm{c}}$ Department of Electrical engineering, University of California, Los Angeles, Los Angeles, California 90095, United States

${ }^{\mathrm{d}}$ SKKU Advanced Institute of Nanotechnology (SAINT) and Department of Nanoengineering, Sungkyunkwan University, Suwon 16419, Republic of Korea

e Division of Materials Science and Engineering, Hanyang University, Seoul 04763, Republic of Korea

${ }^{\mathrm{f}}$ Department of Intelligent Mechatronics Engineering, Sejong University, 209 Neungdong-ro, Gwangjin-gu, Seoul, 05006, Republic of Korea

Corresponding Authors: Y. Y. (yangy@ucla.edu), Y. S. R. (youseung@ sejong.ac.kr)

\section{KEYWORDS \\ Healthcare monitoring, Organic photodetector, Pulsed Oximetry, Wearable electronics, Bioelectronics}




\begin{abstract}
In light of the importance of and challenges inherent in realizing a wearable healthcare platform for simultaneously recognizing, preventing, and treating diseases while tracking vital signs, the development of simple and customized functional devices has been required. Here, we suggest a new approach to make a stretchable light waveguide which can be combined with integrated functional devices, such as organic photodetectors and nanowire-based heaters, for multifunctional healthcare monitoring. Controlling the reflection condition of the medium gave us a solid design rule for strong light emission in our stretchable waveguides. Based on this rule, the stretchable light waveguide (up to 50\% strain) made of polydimethylsiloxane was successfully demonstrated with strong emissions. We also incorporated highly sensitive organic photodetectors and silver nanowire-based heaters with the stretchable waveguide for the detection of vital signs, including heart rate, deep breathing, coughs, and blood oxygen saturation. Through these multifunctional performances, we have successfully demonstrated that our stretchable light waveguide has a strong potential for multifunctional healthcare monitoring.
\end{abstract}


Recent advances in wearable clinical and healthcare technologies are creating a new opportunity in self-care for recognizing, preventing, and treating diseases while tracking vital signs for health outcomes. ${ }^{1-6}$ The new form factor of hybrid platforms in stretchability and conformity is enabling the real wearable environment to adapt to the human body using rough and/or soft curvilinear geometry. ${ }^{7-8}$ The emission and absorption of light as non-destructive monitoring in the human body have attracted the attention of researchers seeking to give multiple opportunities for monitoring vital signs to realize personalized photo-medicine. ${ }^{9-10}$ The photochemical and photophysical effects of light on tissues affect various biological changes through phototherapy, including complicated electron transfer in electronically excited states in tissues leading to the acceleration of wound healing in mitochondrial metabolism, adenosine triphosphate (APT) production, and skeletal muscle regeneration. ${ }^{11-13}$ In light transmit applications, pulsed oximetry has been used as a non-invasive monitoring system to measure the heart rate and arterial blood oxygen concentration and has been commercially implemented in smart instruments (e.g., smart phones, watches, bands). Two kinds of light-emitting diodes (LEDs) with the reverse response characteristics of oxy- and deoxyhemoglobin in the blood are used as the emitter, and one photodetector is detected to determine how many photons are vertically transmitted through the tissue by the different volume of blood. This ratio of oxy- and deoxyhemoglobin gives the arterial blood oxygen saturation. ${ }^{14}$ On the other hand, the recent requirement for real-time monitoring of the human body has been facing the other side of novel applications; people are focusing on needing to know something more meaningful for their health. As a result, commercial applications of monitoring platforms have not yet been able to apply stretchable and wearable environments and simultaneous real-time tracking of the human body, which are significant challenges to realizing wearable healthcare. ${ }^{15-16}$ 
Here, we demonstrate a simple but unique approach to making a stretchable waveguide that can be easily integrated into other functional devices, including micro LEDs, organic photodetectors, and heaters. Each component plays a specific role. For example, LEDs emit light to interact with our body, detectors work as reading information from the body, and the metal heaters reflect and increase the volume of blood vessels. The new platform presents multi-functional wearable photomedical devices as non-destructive monitoring devices. Using our device, we successfully confirmed that a finger strap-based pulse oximeter could measure human vital signals, such as heart rate, arterial oxygen saturation $\left(\mathrm{S}_{\mathrm{a}} \mathrm{O}_{2}\right)$, respiratory rate, and emotional and physical variations (i.e., sigh, cough). We believe that our study suggests a new type of approach for realizing a realtime monitoring healthcare system.

\section{Results and Discussion}

Conventional pulsed oximetry consists of two parts: micro-LEDs and photo sensors, which can be arrayed as either reflection or transmission types. To improve the sensitivity and reduce the signalto-noise ratio during the measurement, the large area light emission with multiple LEDs, multiphoto sensor arrays, or noise-reduction algorithms can be considered, but these approaches can increase production costs. ${ }^{17-18}$ Thus, we constructed a new type of light guide plate based on polydimethylsiloxane (PDMS) for the large area emissive pulsed oximetry with a photothermal therapy function (Figure 1). We examined the effect of the micro structures of the light guide plate (LGP) with PDMS using the simulation shown in Figure 1A and 1B. Cone-based microstructures confirmed that emission light on the side of the $\mu$-LED was effectively delivered to the top side, perpendicularly. The effect of micropatterns on the emission characteristics of devices was analyzed using two-dimensional finite-difference time-domain (2D FDTD) simulations. The 
electric field intensities $(|E|)$ showed that most of the field was guided inside PDMS film by total internal reflection (Figure 1A), as the critical angle is around $45^{\circ}$ at the interface between PDMS ( $n=1.41)$ and air $(n=1.0)$, which is comparable to the beam angle of the LED source. On the other hand, it was clearly shown that the portion of the electric field radiated above the film was significantly increased, because of the $54.7^{\circ}$-slanted facets of the micropatterns (Figure 1B). This is also substantiated from the relative intensities of the energy flux along the z-direction $\left(\left|P_{z}\right|\right)$, which is perpendicular to the direction of light propagation. Based on the simulation, we fabricated different shapes of LGP films with two cone-based lines (width $100 \mu \mathrm{m} x$ length $12,000 \mu \mathrm{m} x$ height $100 \mu \mathrm{m}$ x spacing $100 \mu \mathrm{m}$; width $200 \mu \mathrm{m}$ x height $200 \mu \mathrm{m}$ x length $12,000 \mu \mathrm{m}$ x spacing $200 \mu \mathrm{m}$ ), random shapes, and cone structures (width $200 \mu \mathrm{m}$ x length $200 \mu \mathrm{m}$ x height $200 \mu \mathrm{m}$ x spacing $100 \mu \mathrm{m}$ ), and the conditions were shown, sequentially (Figure 1C). The cone-based line structures showed the best light emission in our conditions. To apply them to wearable instruments, we performed a strain test of LGP films under the strain values ranging from 0-50\% (Figure 1D). The light emission performance showed no degradation under the 50\% strain (Figure S1). All conditions showed good emissions, and it was highly expected that the same would be true when applied to the finger or any portion of the human body. In addition, we embedded AgNWs to apply thermal energy beyond only the monitoring platform, which can either accelerate phototherapy or give extra functions while working as the reflector to enhance the light emission (Figure S2). The temperature was increased up to a maximum of $\sim 55^{\circ} \mathrm{C}$ (Figure 1E), and it was possible to apply infrared or blue light therapy with thermal addition for effective treatment.

The light sources of pulsed oximetry consisted of red and NIR regions to calculate the fraction of oxy-hemoglobin relative to deoxy-hemoglobin in the blood. ${ }^{19}$ Red and NIR regions also easily ensure effective transmission to arterial blood and tissues. ${ }^{20}$ In the photodetector part, the high 
sensitivity of the two light regions is essential for calculating $\mathrm{SpO}_{2}$. Here, we constructed easily and simply processed organic photodetectors with the bulk-heterojunction polymers of poly[2,7(5,5-bis-(3,7-dimethyloctyl)-5H-dithieno[3,2-b:2',3'-d]pyran)-alt-4,7-(5,6-difluoro-2,1,3benzothia diazole)] (PDTP-DFBT) with [6,6]-phenyl C71-butyric acid methyl ester $\left(\mathrm{PC}_{71} \mathrm{BM}\right)$ as an acceptor (Figure 2A-C). ${ }^{21}$ Organic photodetectors have also attracted researchers' attention for flexible sensor applications due to their high flexibility. The bandgap of PDTP-DFBT is as low as $1.7 \mathrm{eV}$, which can be applied to the light absorption of the NIR region, which even covers wavelengths up to $900 \mathrm{~nm}$, as shown in Figure S3 (here, we used an $\mu$-LED with the wavelength of $850 \mathrm{~nm}$ ). External quantum efficiency (EQE) showed 21.0\%, 24.9\%, and 29.4\% at the 450, 630, and $850 \mathrm{~nm}$ wavelengths using monolithic LED light sources while demonstrating broad spectrum ranges from 350 to $900 \mathrm{~nm}$ (Figure 2D). The magnitude of photocurrent versus dark current reached over $10^{4}$ at the photo power density of $1 \mathrm{~mW} \mathrm{~cm}^{-2}$, regardless of the light source (Figure 2E). The photoresponse measurement of the device was also conducted at $450 \mathrm{~nm}$ to apply bilirubin photo-oxidation for jaundice treatment. ${ }^{22}$ The performance of the photodiode was evaluated using responsivity $(\mathrm{R})$, detectivity $\left(\mathrm{D}^{*}\right)$, linear dynamic range (LDR), and quantum efficiency. We measured the noise current to calculate the exact detectivity value, which was relatively higher than the shot noise level (Figure S4). The detectivity was calculated using the Noise Equivalent Power (NEP) as follows:

$$
D^{*}=\frac{\left(A_{d} B\right)^{1 / 2}}{i_{n} / R}
$$

where $A_{d}$ is the effective area of the detector, $B$ is the electrical bandwidth, and $i_{n}$ is the noise current. The responsivity, $R$, is proportional to the quantum yield of the photodetector and is the key factor of the phototransistor's evaluation, requiring a high conversion ratio between the incident photons to photoexcited electrons and holes to realize the high external quantum 
efficiency (EQE). Finally, $q$ is the elementary charge $\left(1.602 \times 10^{-19} \mathrm{C}\right)$. The detectivity and responsivity reached $1.1 \times 10^{8}$ Jones and $0.21 \mathrm{~A} \mathrm{~W}^{-1}$, respectively, at the light illumination of 850 $\mathrm{nm}$ with a photo power density of $1 \mathrm{~mW} \mathrm{~cm}{ }^{-2}$. The values of detectivity were also shown in $1.0 \times$ $10^{8}$ and $1.4 \times 10^{8}$ Jones, respectively, at the illumination light of 450 and $630 \mathrm{~nm}$, which showed good photosensitivity at broad spectrum ranges. The value of LDR is proportional to the linearity of the photosensitivity as light intensities increase. LDR can be determined by

$\mathrm{LDR}=20 \log \left(I_{\text {ph }}^{*} / I_{\text {dark }}\right)$

where $I_{p h}^{*}$ is the photocurrent, measured at a light intensity of $1 \mathrm{~mW} \mathrm{~cm}{ }^{-2}$. The LDR and quantum efficiency $(\mathrm{QE})$ response of the PDTP-DFBT:PC ${ }_{71} \mathrm{BM}$ photodetector were calculated within the power density range from $8.0 \times 10^{-7}$ to $4.3 \mathrm{~mW} \mathrm{~cm}^{-2}$ (calculated incident photon flux density range from $2.5 \times 10^{9}$ to $1.8 \times 10^{16}$ numbers $^{-1} \mathrm{~cm}^{-2}$ ) at $850 \mathrm{~nm}$ (Figure $2 \mathrm{~F}$ ). The LDR showed linearity as an increase of the photon flux density; the QE also showed constant values of $0.43 \pm 0.11$. The calculated LDR and QE of the device were $129 \mathrm{~dB}$ and 0.32 , respectively, at $0 \mathrm{~V}$.

Figure 3A shows the integration of stretchable LGP with the AgNWs matrix, $\mu$-LEDs, and an organic photodetector. In order to maintain contact with the finger, an organic photodetector was also embedded in the PDMS template. All parts were then put in the bandage as shown in the picture. As the principle of reading oxygen saturation via optoelectronic devices is based on the difference between the absorption of oxygenated hemoglobin $\left(\mathrm{HbO}_{2}\right)$ and deoxygenated hemoglobin $(\mathrm{Hb})$ at two different wavelengths, we incorporated two different wavelength LEDs into our device platform to track the oxygen saturation in the blood. Considering the absorption property of $\mathrm{HbO}_{2}$ and $\mathrm{Hb}, 630 \mathrm{~nm}$ and $830 \mathrm{~nm}$ wavelengths were chosen as they have clear differences in absorption properties (Figure S5). As shown in Figure 3B, the photoplethysmogram (PPG) signals were acquired clearly under both the $630 \mathrm{~nm}$ and $850 \mathrm{~nm}$ wavelengths. Figure S6 
shows the entire system during the measurement. As the PPG indicates the blood volume chances, understanding PPG gives useful diagnostic information, including arterial oxygen saturation $\left(\mathrm{S}_{\mathrm{a}} \mathrm{O}_{2}\right) . \mathrm{S}_{\mathrm{a}} \mathrm{O}_{2}$ can be calculated by using the molar absorptivity of deoxy- and oxy-hemoglobin in the red $(\lambda=630 \mathrm{~nm})$ and $\operatorname{NIR}(\lambda=850 \mathrm{~nm})$ regions and the ratio of light transmission to red and NIR, as shown in the following equation ${ }^{19}$ :

$S_{a} O_{2}\left(R_{O S}\right)=\frac{\varepsilon_{N I R, H b}-\left(\varepsilon_{R E D, H b} \times \frac{\ln \left(T_{n, N I R}\right)}{\ln \left(T_{n, R E D}\right)}\right)}{\left(\varepsilon_{N I R, H b}-\varepsilon_{N I R, H b O_{2}}\right)+\left(\left(\varepsilon_{R E D, H b O_{2}}-\varepsilon_{R E D, H b}\right) \times \frac{\ln \left(T_{n, N I R}\right)}{\ln \left(T_{n, R E D}\right)}\right)}$

$\varepsilon_{N I R, H b}, \varepsilon_{R E D, H b}, \varepsilon_{N I R, H b O_{2}}$, and $\varepsilon_{R E D, H b O_{2}}$ are the molar absorptivity of the deoxy-hemoglobin at NIR and red, respectively. The ratio of $\ln \left(T_{n, N I R}\right) / \ln \left(T_{n, R E D}\right)$ can be calculated by the normalized transmitted light intensities. The calculated $\mathrm{S}_{\mathrm{a}} \mathrm{O}_{2}$ indicated an average 98-99\% for a normally healthy person. In addition to oxygen saturation, determining how the wavelet transforms with the respiratory rate is a critical issue in accidents and emergencies. The respiratory rate change was examined through our devices as the volume of blood vessels can be tracked by the change in light interacting with the body. The typical respiratory rate for a healthy adult at rest is 12 breath/min on average. ${ }^{23}$ Based on our experiment, the participant showed normal status as 11 breaths/min (Figure 3C), which indicates that our device effectively read the respiratory rate.

In addition, while tracking the respiratory rate, we observed another pattern in the signal, which was interesting. The different signatures occurred when the participant tried to give specific behavior patterns, such as sighs and coughs. For example, when the participant sighed, the baseline of the signal decreased for about $10 \mathrm{sec}$. It then slowly recovered until being close to the normal status as the breathing condition returned to normal. ${ }^{24}$ As the sigh rate and respiratory variability are strongly related to mental load and sustained attention, this kind of tracking of the sigh signal could be adapted as a simple and objective screening for major depressive disorder in a real-time 
monitoring platform, although the exploration of a detailed mechanism should be addressed in future research. In the case of coughs, the signal showed a distorted signature, regardless of the number of times, due to the abrupt change in respiratory functioning. However, the distorted signature of coughs may not be distinguishable from strong motion artifacts, so further studies are warranted in terms of the qualitative comparison of motion signals. This parameter would undoubtedly be useful as another indicator for tracking health conditions (Figure 3D). Figure 3E shows the different response signals of non-heat (blue, below line) and heat (red, upper line) at a temperature of $\sim 50^{\circ} \mathrm{C}$ (Figure $\left.\mathrm{S} 7\right)$.

As the signal is much weaker than the signal coming from the respiratory rate, the transimpedance amplifier was connected to the devices. To increase the temperature, AgNWs were embedded in the LGP. Thermotherapy is a popular treatment for improving the symptoms of osteoarthritis, improving circulation and relaxing muscles, and promoting pain relief with the increment of blood flow. ${ }^{25}$ As a result, the change to the baseline in the PPG signal indirectly recorded the effect of thermal treatment in the tissue. To demonstrate the complete system for transmitting the PPG information, we also prepared the customized pulsed oximetry with wireless communication to the tablet and obtained fine signals of respiratory and heart rate as well as $\mathrm{SpO}_{2}$. As shown in Figure 4A and 4B, an analog front-end (AFE4490) for pulse oximeters and Bluetooth SoC (nRF51822) were utilized to extract real-time recording through wireless communication. The detailed circuit designs are included in Figures S8-S10. Through the wireless communication system, the same quality of PPG information was obtained on our mobile screen without any noticeable noise when tracking the health condition (Figures 4C and 4D). We also compared our device with a state-ofthe-art multifunctional healthcare platform in Table 1.

\section{Conclusion}


In summary, we introduced wearable, photonic-detectable, and stimulus healthcare platforms using stretchable PDMS LGP, organic PDs, and AgNWs, exploring nanomaterials and fabrications. We utilized the principle of absorption difference for two different wavelengths to track oxygen concentration in hemoglobin and the change in blood vessel volume to provide information on several physiological phenomena, such as breathing condition. Based on the platform, we successfully demonstrated the communication of the PPG information, including heart rate, oxygen saturation, respiratory rate, coughs, and sighs. This information could give new indicators for determining a detailed health status beyond conventional information. In addition, we incorporated the platform with a wireless communication system to transmit information outside of the devices for actual applications. We believe that this new type of approach could be a useful platform for tracking vital signs to maintain a healthy life.

\section{Experimental Section}

\section{Materials}

SYLGARD 184 silicone elastomer kits were purchased from Ellsworth Adhesives (Germantown, WI, USA) for PDMS LGPs. Blue, red, and infrared $\mu$-LEDs $(\lambda=450,630$, and $850 \mathrm{~nm})$ were

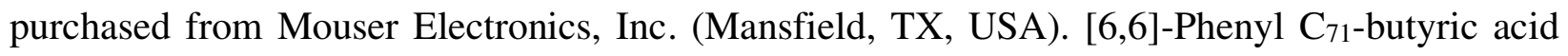
methyl ester was purchased from Nano-C (Westwood, MA, USA). 1,2-dichlorobenzene was purchased from Sigma-Aldrich (St. Louis, MO, USA). AgNWs with an average diameter and length of around $90 \mathrm{~nm}$ and $30 \mu \mathrm{m}$, respectively, were obtained from Blue Nano Inc. (Charlotte, NC, USA).

Fabrication of Si mold with trench structures 
We started with silicon wafer (100) orientation, aligning the trenches to <110> flats. Silicon nitride $(1 \mu \mathrm{m})$ was deposited in the $\mathrm{KOH}$ etch mask layer using plasma-enhanced chemical vapor deposition (PECVD) (STS, MESC Multiplex PECVD). After the deposition, the silicon wafer was baked until dehydration $\left(120^{\circ} \mathrm{C}\right.$ for $\left.10 \mathrm{~min}\right)$, followed by HMDS vapor coating for $10 \mathrm{~min}$. Photoresist AZ5214 was spin-coated at $3000 \mathrm{rpm}$ for $30 \mathrm{sec}$ and soft-baked at $100^{\circ} \mathrm{C}$ for $2 \mathrm{~min}$. The wafer was selectively exposed to a UV mask aligner (Karl Suss, MA6) using a photomask with rectangular openings for the trenches $(100 \mu \mathrm{m})$. The wafer was exposed to UV for $10 \mathrm{sec}$ and then developed using AZ300K in DI water (1:4) for $60 \mathrm{sec}$. Using patterned photoresist as the etch mask, silicon nitride was dry-etched in RIE (STS, MESC Multiplex AOE) to reveal the silicon surface. The wafer with the patterned nitride layer was etched in $30 \% \mathrm{KOH}$ in DI water at $80^{\circ} \mathrm{C}$ until the etching stopped. Trenches with a sharp tip were etched at a $54^{\circ}$ angle and in multiple dimensions of rectangular openings. As a result, pyramid trenches were etched in multiple dimensions. The silicon mold was treated with HMDS before pouring PDMS for easy release of the film.

\section{Fabrication of PDMS LGP}

Mixtures of Sylgard 184 elastomer base and curing agent (10:1) were thoroughly mixed. Wired $\mu$ LEDs were placed perpendicularly into a petri dish containing the Si master, and the mixture was poured, degassed in a vacuum desiccator, and cured at $70 \mathrm{C}$ for $5 \mathrm{~h}$. Afterwards, the PDMS LGPs with $\mu$-LEDs were carefully removed from the Si masters. For the AgNW heater preparation, diluted AgNW solutions were coated onto PDMS with a brush and were pre-baked at $70^{\circ} \mathrm{C}$.

\section{Fabrication of organic photodetectors}

The patterned ITO substrate was sequentially washed with isopropanol, acetone, and distilled water. The pre-cleaned patterned ITO substrates were first treated with UV-ozone for 15 min. 
PEDOT:PSS layers were spin-coated on the ITO substrates at $2000 \mathrm{rpm}$ for $60 \mathrm{sec}$. PDTPDFBT:PC ${ }_{71} \mathrm{BM}(1: 2)$ was dissolved in 1,2-dichlorobenzene at a concentration of $7.5 \mathrm{mg} \mathrm{mL}^{-1}$ and was spin-coated on the ITO/PEDOT:PSS at $5000 \mathrm{rpm}$ for $30 \mathrm{sec}$. The samples were transferred into the evaporation chamber for fabricating the $\mathrm{Al}$ electrodes $(100 \mathrm{~nm})$ at a base pressure below $5 \times 10^{-6}$ Torr, and the active area was fixed at $0.1 \mathrm{~cm}^{2}$.

Fabrication of silver nanowire (AgNW) for a stretchable heater

AGNWs with an average diameter of $90 \mathrm{~nm}$ and an average length of $30 \mu \mathrm{m}$ were purchased from Blu Nano Inc. (Charlotte, NC, USA). AgNWs were dispersed in ethanol with a concentration of $2.5 \mathrm{mg} / \mathrm{mL}$ and were spun on PDMS at a speed of $2000 \mathrm{rpm}$. They were cured at around $80^{\circ} \mathrm{C}$ for $1 \mathrm{~h}$ and worked as a stretchable heater.

\section{Simulation of stretchable LGP}

The electric field profiles were calculated using 2D FDTD simulations (FDTD solutions, Lumerical, Vancouver, Canada). Randomly polarized electric dipole sources surrounded by slanted mirrors were employed in the simulation as a source to mimic the LED source with the beam angle of $54.7^{\circ}$ used in the experiment. The dimension of the device was scaled down to the film thickness of $80 \mu \mathrm{m}$ and the pattern width of $8 \mu \mathrm{m}$ in the simulation, due to limitations in computation resources. The qualitative analysis derived from the scaled dimension was still valid because the realistic and scaled dimensions were both in the ray optics regime.

\section{Development of Android-based software and circuits}

Integrated analog front-end for pulse oximeters (AFE4490, Texas Instrument, Texas, USA) was used to process the signals and power control of photodiode and two LEDs. To process signals with wireless communication, an ultra-low power $2.4 \mathrm{GHz}$ wireless system on chip (nRF51822, Nordic Semiconductor, Oslo, Norway) was integrated. The nRF51822 (Multiprotocol Bluetooth 
low energy/2.4 GHz RF system on chip) SoC was used for the main processor, and the circuit design was made by Eagle CAD. For the software, BLE system API of Android was used as communication codes for Bluetooth energy. All the data were visualized by open source-based GraphView through Github. 
Table I. Summary of multi-functional healthcare platforms research.

\begin{tabular}{|c|c|c|c|c|c|}
\hline Purpose & Active Material & Mechanism & Stimulus & Communication & Ref. \\
\hline Saliva analysis & Graphene & Resistance change & Bacteria & RFID & 26 \\
\hline Odor analysis & CNT, Polymer & Resistance change & $\begin{array}{c}\text { Ammonia, } \\
\text { Acetic acid, } \\
\text { Acetone, } \\
\text { Etahnol }\end{array}$ & ZigBee wireless & 27 \\
\hline $\begin{array}{c}\text { Oxygen } \\
\text { concentration }\end{array}$ & Organic materials & $\begin{array}{l}\text { Light attenuation } \\
\text { difference }\end{array}$ & $\begin{array}{c}\text { Oxygen } \\
\text { concentration }\end{array}$ & None & 15 \\
\hline $\begin{array}{l}\text { Wound } \\
\text { monitoring }\end{array}$ & Carbon ink & $\begin{array}{l}\mathrm{pH} \text { change } \\
\text { detection }\end{array}$ & Uric acid & RFID/NFC & 28 \\
\hline $\begin{array}{l}\text { Sweat rate } \\
\text { monitoring }\end{array}$ & $\mathrm{CoCl}_{2}, \mathrm{pHEMA}$ & $\begin{array}{c}\text { Optical } \\
\text { colorimetry }\end{array}$ & $\begin{array}{l}\text { pH, lactate, } \\
\text { chloride, } \\
\text { glucose }\end{array}$ & NFC & 29 \\
\hline Sweat sensor & $\begin{array}{l}\text { Sodium \&Potassium } \\
\text { ISEs, } \mathrm{Ag} / \mathrm{AgCl}\end{array}$ & $\begin{array}{l}\text { Electrochemical- } \\
\text { potentiometry }\end{array}$ & $\begin{array}{l}\text { Glucose, } \\
\text { Lactate }\end{array}$ & Wireless FPCB & 30 \\
\hline $\begin{array}{l}\text { Dehydration, } \\
\text { Diabetes } \\
\text { monitoring }\end{array}$ & $\begin{array}{l}\text { PEDOT, Grapehen, } \\
\text { PANi }\end{array}$ & $\begin{array}{l}\text { Resistance } \\
\text { change, } \\
\text { Electrochemical } \\
\text { amperometry }\end{array}$ & $\begin{array}{l}\text { Humidity, } \\
\text { glucose, } \mathrm{pH}\end{array}$ & Bluetooth & 31 \\
\hline Iontophoresis & $\begin{array}{l}\text { Sodium ISEs, } \\
\mathrm{Ag} / \mathrm{AgCl}\end{array}$ & $\begin{array}{l}\text { Electrochemical- } \\
\text { potentiometry and } \\
\text { amperometry }\end{array}$ & $\begin{array}{l}\text { Glucose, } \\
\text { sodium, } \\
\text { chloride }\end{array}$ & Wireless FPCB & 32 \\
\hline $\begin{array}{l}\text { Heart rate, } \mathrm{SpO} 2, \\
\text { respiratory, } \\
\text { phototherapy, } \\
\text { phototherapeutic }\end{array}$ & $\begin{array}{c}\text { Organic } \\
\text { photodetector, } \mu- \\
\text { LED }\end{array}$ & $\begin{array}{c}\text { Light attenuation } \\
\text { difference, } \\
\text { photooxidation }\end{array}$ & $\begin{array}{l}\text { Oxygen } \\
\text { concentration, } \\
\text { Changes in } \\
\text { Blood volume }\end{array}$ & Bluetooth & Our work \\
\hline
\end{tabular}




\section{Figures}
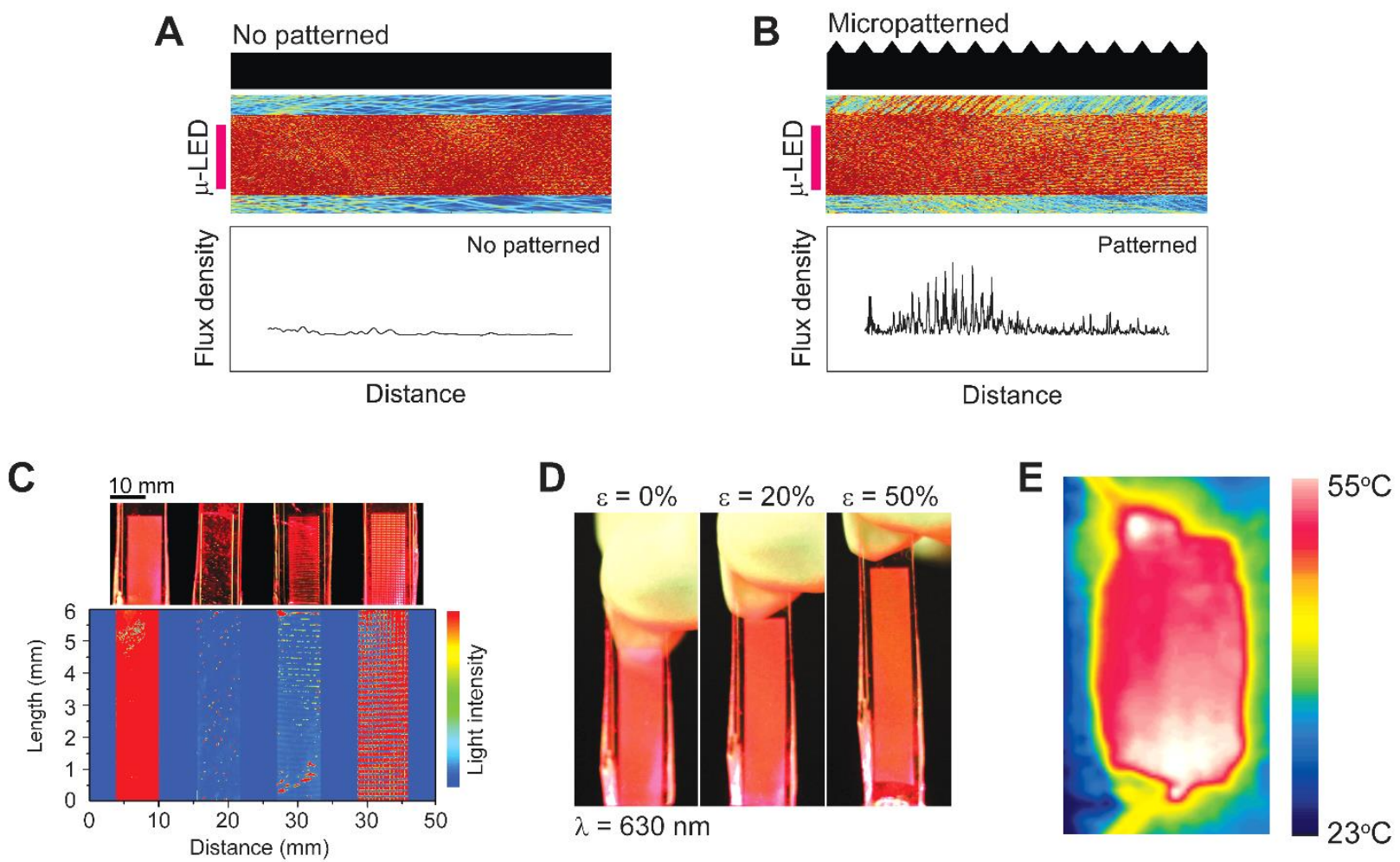

Figure 1. Stretchable PDMS LGP with AgNW matrix. The simulation results of light traces and flux density of LGP (A) without patterns and (B) with micro patterns (W100 $\mu \mathrm{m} \times \mathrm{H} 100 \mu \mathrm{m})$ according to the $\mu$-LED emission. (C) Emissive images and mapping of light guide plates with two cone-based lines (width $100 \mu \mathrm{m}$ x length 12,000 $\mu \mathrm{m}$ x height $100 \mu \mathrm{m}$ x spacing $100 \mu \mathrm{m}$; width $200 \mu \mathrm{m} \times$ height $200 \mu \mathrm{m}$ x length $12,000 \mu \mathrm{m}$ x spacing $200 \mu \mathrm{m})$, random shapes, and cone structures (width $200 \mu \mathrm{m}$ x length $200 \mu \mathrm{m}$ x height $200 \mu \mathrm{m}$ x spacing $100 \mu \mathrm{m}$.). (D) Strain tests of light guide plates with the strain values ranging from $0-50 \%$. (E) IR image of light guide plate embedded with $\mathrm{AgNW}$ heater, and the temperature was increased to $\sim 55^{\circ} \mathrm{C}$. 
A

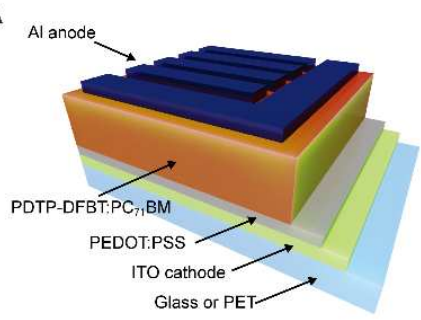

D

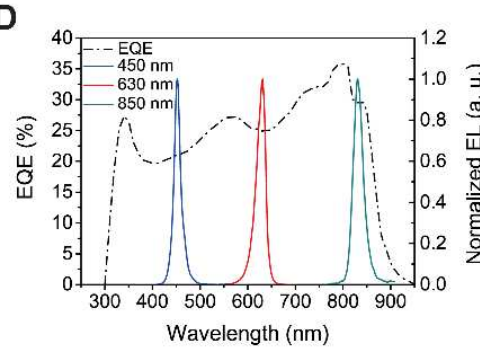

B

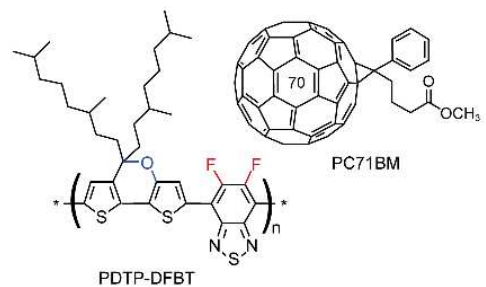

$E$

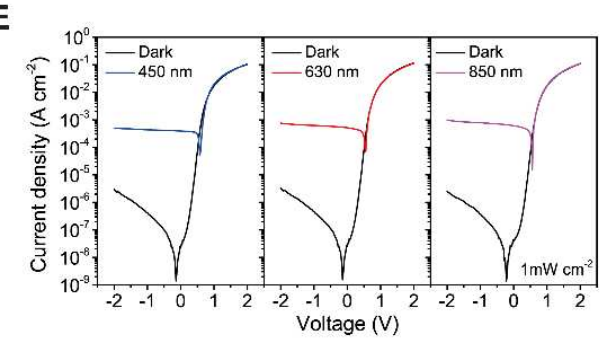

C
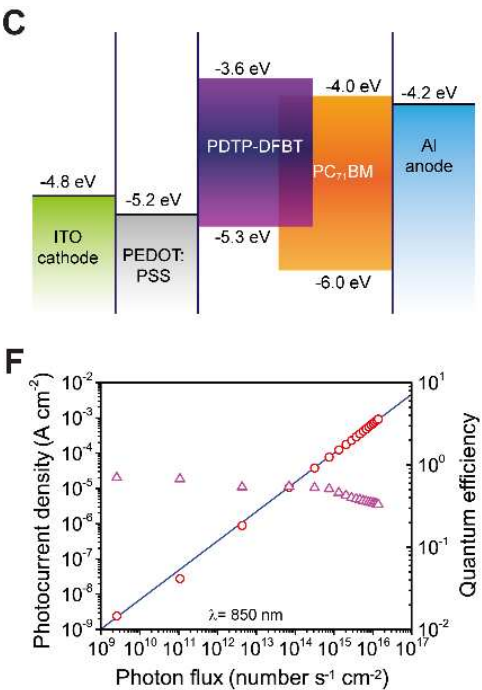

Figure 2. Organic photodetectors. (A) The schematic of the organic photodetector. (B) PDTPDFBT and $\mathrm{PC}_{71} \mathrm{BM}$ were blended and used as the active layer. (C) The band structure of the organic photodetector. The low bandgap polymer PDTP-DFBT showed the HOMO and LUMO levels of $-3.6 \mathrm{eV}$ and $-5.3 \mathrm{eV}$, respectively. (D) The measured external quantum efficiency of PDTP-DFBT:PC ${ }_{71} \mathrm{BM}$ photodetector and the electroluminescence of $\mu$-LEDs with blue ( $\lambda=450$ $\mathrm{nm})$, red $(\lambda=630 \mathrm{~nm})$, and IR $(\lambda=850 \mathrm{~nm})$. The EQE covers wavelengths ranging from 320 to 920 $\mathrm{nm}$ and is compatible with desired $\mu$-LED lights. (E) The current-voltage characteristics of PDTPDFBT:PC ${ }_{71} \mathrm{BM}$ photodetector under the 450,630 , and $850 \mathrm{~nm}$ wavelengths at the photo power density of $1 \mathrm{~mW} \mathrm{~cm}^{-2}$. (F) The linear dynamic range (LDR) performance and quantum efficiency at the $850 \mathrm{~nm}$ wavelength. The LDR and QE are $129 \mathrm{~dB}$ and 0.32 at $0 \mathrm{~V}$. 
A

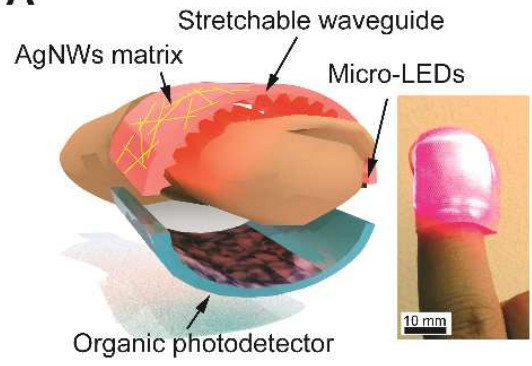

D

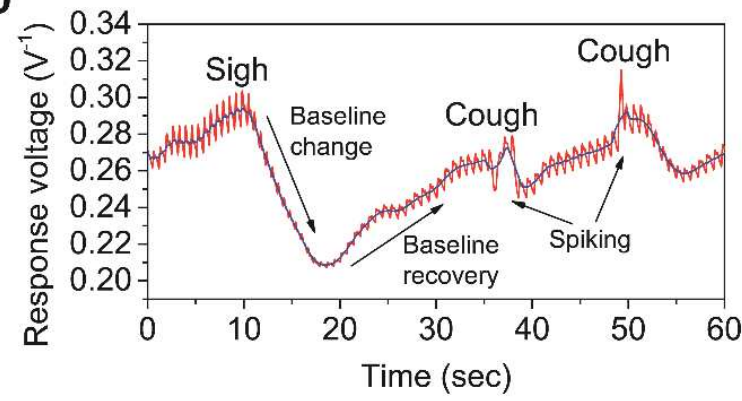

B

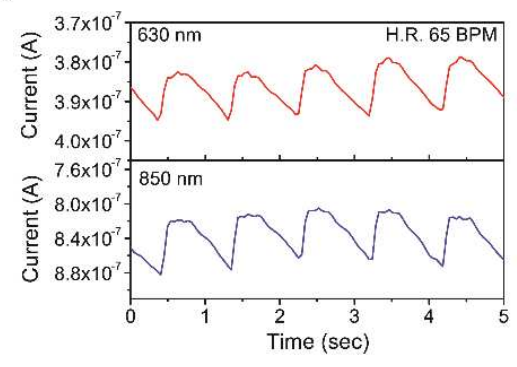

C

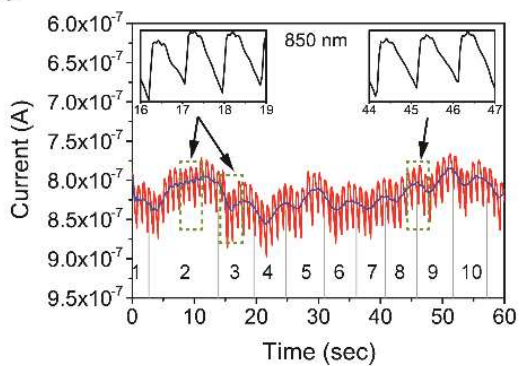

E

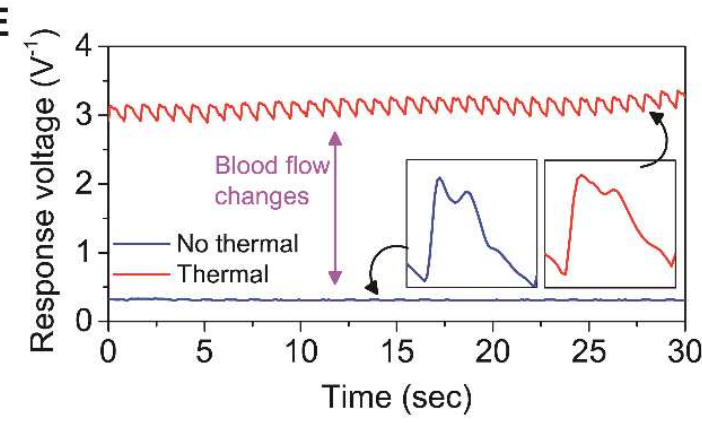

Figure 3. Stretchable LGP-based pulsed oximetry. (A) The design schematic of stretchable pulsed oximetry is integrated with a stretchable AgNWs heater and $\mu$-LEDs embedded in PDMS LGP and PDTP-DFBT:PC 71 BM photodetectors. (B) PPG signal acquired using $\mu$-LEDs with 630 and $850 \mathrm{~nm}$ and calculated $\mathrm{S}_{\mathrm{a}} \mathrm{O}_{2}$ indicating 98-99\%. (C) The respiratory rate signal was acquired for $60 \mathrm{~s}$ and showed 11 breaths $\mathrm{min}^{-1}$ at rest. (D) The PPG signal tracking was acquired under nonspecific behaviors in terms of a deep sigh and two coughs. The baseline changed significantly when the participant made a deep sigh, and the signature showed a big spike during a cough. (E) The change in the blood flow rate was confirmed by increasing the temperature of the finger using the AgNWs heater $\left(\sim 40^{\circ} \mathrm{C}\right)$, which indicated the increment of voltage level of about 3 times from the expansion of capillary blood flow. 

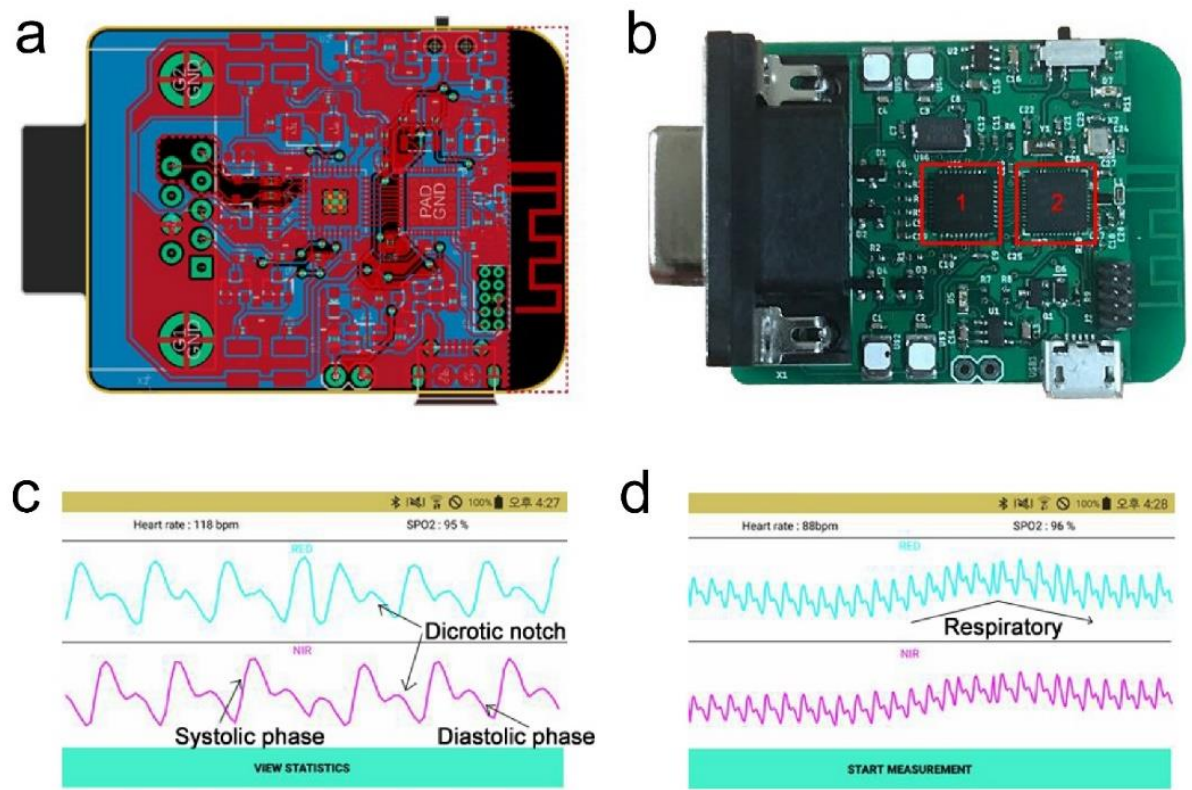

Figure 4. Bluetooth information communication (A) Artwork and (B) actual board image of PCB with all chips. 1 and 2 indicate analog front-ed (AFE4490) for pulse oximeters and Bluetooth SoC (nRF51822), respectively. (C, D) Operation of pulsed oximetry with stretchable PDMS LGP. 


\section{ASSOCIATED CONTENT}

Supporting Information. Absorptivity of oxy- and deoxy-hemoglobin and the position of applied $\mu$-LEDs, noise current measurement of photodetectors, FT-IR spectrum of bilirubin for pre- and photo-treatment, induced temperature of $\mathrm{AgNW}$ heater, circuit design and actual instrument operation of pulsed oximeter platform are included. This material is available free of charge via the Internet at http://pubs.acs.org.

\section{AUTHOR INFORMATION}

\section{Corresponding Authors}

Yang Yang - Department of Materials Science Engineering, University of California, Los Angeles, Los Angeles, California 90095, United States; https://orcid.org/0000-0001-8833-7641; Email: yangy@ucla.edu

You Seung Rim - Department of Intelligent Mechatronics Engineering, Sejong University, 209 Neungdong-ro, Gwangjin-gu, Seoul, 05006, Republic of Korea; https://orcid.org/0000-00024281-8818; Email: youseung @ sejong.ac.kr

\section{Other Authors}

Donghyuk Kim - Department of Bioengineering, University of California Los Angeles, Los Angeles, California 90095, United States

Sheng-Yung Chang - Department of Materials Science and Engineering, University of California, Los Angeles, Los Angeles, California 90095, United States

Janet Hur - Department of Materials Science and Engineering, University of California, Los Angeles, Los Angeles, California 90095, United States

Hyunseok Kim - Department of Electrical engineering, University of California, Los Angeles, Los Angeles, California 90095, United States

Jin-Wook Lee - SKKU Advanced Institute of Nanotechnology (SAINT) and Department of Nanoengineering, Sungkyunkwan University, Suwon 16419, Republic of Korea 
Bowen Zhu - Department of Materials Science and Engineering, University of California, Los Angeles, Los Angeles, California 90095, United States

Tae-Hee Han - Division of Materials Science and Engineering, Hanyang University, Seoul 04763, Republic of Korea

Chanyeol Choi - Department of Electrical engineering, University of California, Los Angeles, Los Angeles, California 90095, United States

Diana. L. Huffaker - Department of Electrical engineering, University of California, Los Angeles, Los Angeles, California 90095, United States

Dino Di Carlo-Department of Bioengineering, University of California Los Angeles, Los Angeles, California 90095, United States

\section{Author Contributions}

The manuscript was written through contributions of all authors. All authors have given approval to the final version of the manuscript. $\ddagger$ S.H.B. and D. K. contributed equally to this work.

Notes
The authors declare no competing financial interest.

\section{Funding Sources}

This work was supported by the National Research Foundation of Korea (NRF) grant funded by the Korea government (MSIT) (No. 2020R1A2C1013693)

\section{ACKNOWLEDGMENT}

Authors would like to thank Axden (Sang-Jin Jang) for valuable discussions on integrated circuits and software, respectively. 


\section{REFERENCES}

1. Kwak, Y. H.; Kim, W.; Park, K. B.; Kim, K.; Seo, S., Flexible Heartbeat Sensor for Wearable Device. Biosens. Bioelectron. 2017, 94, 250-255.

2. Cai, F.; Yi, C. R.; Liu, S. C.; Wang, Y.; Liu, L. C.; Liu, X. Q.; Xu, X. M.; Wang, L., Ultrasensitive, Passive and Wearable Sensors for Monitoring Human Muscle Motion and Physiological Signals. Biosens. Bioelectron. 2016, 77, 907-913.

3. Yeo, W. H.; Kim, Y. S.; Lee, J.; Ameen, A.; Shi, L. K.; Li, M.; Wang, S. D.; Ma, R.; Jin, S. H.; Kang, Z.; Huang, Y. G.; Rogers, J. A., Multifunctional Epidermal Electronics Printed Directly onto the Skin. Adv. Mater. 2013, 25, 2773-2778.

4. Weenk, M.; van Goor, H.; Frietman, B.; Engelen, L. J. L. P. G.; van Laarhoven, C. J. H. M.; Smit, J.; Bredie, S. J. H.; van de Belt, T. H., Continuous Monitoring of Vital Signs Using Wearable Devices on the General Ward: Pilot Study. JMIR Mhealth Uhealth 2017, 5. e91. 5. Trung, T. Q.; Lee, N. E., Flexible and Stretchable Physical Sensor Integrated Platforms for Wearable Human-Activity Monitoring and Personal Healthcare. Adv. Mater. 2016, 28, 43384372.

6. Lee, H.; Song, C.; Hong, Y. S.; Kim, M. S.; Cho, H. R.; Kang, T.; Shin, K.; Choi, S. H.; Hyeon, T.; Kim, D. H., Wearable/Disposable Sweat-Based Glucose Monitoring Device with Multistage Transdermal Drug Delivery Module. Sci Adv. 2017, 3, e1601314.

7. Jeong, S. H.; Zhang, S.; Hjort, K.; Hilborn, J.; Wu, Z. G., PDMS-Based Elastomer Tuned Soft, Stretchable, and Sticky for Epidermal Electronics. Adv. Mater. 2016, 28, 5830-5836.

8. $\quad$ Kim, D. H.; Lu, N. S.; Ma, R.; Kim, Y. S.; Kim, R. H.; Wang, S. D.; Wu, J.; Won, S. M.; Tao, H.; Islam, A.; Yu, K. J.; Kim, T. I.; Chowdhury, R.; Ying, M.; Xu, L. Z.; Li, M.; Chung, H. J.; Keum, H.; McCormick, M.; Liu, P.; Zhang, Y. W.; Omenetto, F. G.; Huang, Y. G.; Coleman, T.; Rogers, J. A., Epidermal Electronics. Science 2011, 333, 838-843.

9. $\quad$ Meduri, N. B.; Vandergriff, T.; Rasmussen, H.; Jacobe, H., Phototherapy in the Management of Atopic Dermatitis: A Systematic Review. Photodermatol. Photoimmunol. Photomed. 2007, 23, 106-112.

10. Lee, E.; Koo, J.; Berger, T., Uvb Phototherapy and Skin Cancer Risk: A Review of the Literature. Int. J. Dermatol. 2005, 44, 355-360.

11. Yu, W.; Naim, J. O.; Lanzafame, R. J., Effects of Photostimulation on Wound Healing in Diabetic Mice. Laser Surg. Med. 1997, 20, 56-63.

12. Smith, K. C., Laser (and LED) Therapy is Phototherapy. Photomed. Laser Surg. 2005, 23, 78-80.

13. Kim, H. B.; Baik, K. Y.; Choung, P. H.; Chung, J. H., Pulse Frequency Dependency of Photobiomodulation on the Bioenergetic Functions of Human Dental Pulp Stem Cells. Sci. Rep. 2017, 7, 15927.

14. Yelderman, M.; New, W., Evaluation of Pulse Oximetry. Anesthesiology 1983, 59, 349352.

15. Lochner, C. M.; Khan, Y.; Pierre, A.; Arias, A. C., All-Organic Optoelectronic Sensor for Pulse Oximetry. Nat. Commun. 2014, 5, 5745.

16. Yokota, T.; Zalar, P.; Kaltenbrunner, M.; Jinno, H.; Matsuhisa, N.; Kitanosako, H.; Tachibana, Y.; Yukita, W.; Koizumi, M.; Someya, T., Ultraflexible Organic Photonic Skin. Sci Adv. 2016, 2, e1501856.

17. Lee, J.; Jung, W.; Kang, I.; Kim, Y.; Lee, G., Design of Filter to Reject Motion Artifact of Pulse Oximetry. Comput. Stand. Inter. 2004, 26, 241-249. 
18. Hayes, M. J.; Smith, P. R., A New Method for Pulse Oximetry Possessing Inherent Insensitivity to Artifact. IEEE Trans. Biomed. Eng. 2001, 48, 452-461.

19. Shelley, K. H., Photoplethysmography: Beyond the Calculation of Arterial Oxygen Saturation and Heart Rate. Anesth. Analg. 2007, 105, S31-S36.

20. Koide, Y.; Urano, Y.; Hanaoka, K.; Terai, T.; Nagano, T., Development of an SiRhodamine-Based Far-RED to near-Infrared Fluorescence Probe Selective for Hypochlorous Acid and Its Applications for Biological Imaging. J. Am. Chem. Soc. 2011, 133, 5680-5682. 21. You, J. B.; Dou, L. T.; Yoshimura, K.; Kato, T.; Ohya, K.; Moriarty, T.; Emery, K.; Chen, C. C.; Gao, J.; Li, G.; Yang, Y., A Polymer Tandem Solar Cell with 10.6\% Power Conversion Efficiency. Nat. Commun. 2013, 4, 1446.

22. Lightner, D. A.; Linnane, W. P.; Ahlfors, C. E., Bilirubin Photooxidation Products in the Urine of Jaundiced Neonates Receiving Phototherapy. Pediatr. Res. 1984, 18, 696-700. 23. Lin, Y. D.; Chien, Y. H.; Chen, Y. S., Wavelet-Based Embedded Algorithm for Respiratory Rate Estimation from PPG Signal. Biomed. Signal Process. Control 2017, 36, 138145.

24. Vlemincx, E.; Taelman, J.; De Peuter, S.; Van Diest, I.; Van den Bergh, O., Sigh Rate and Respiratory Variability During Mental Load and Sustained Attention. Psychophysiology 2011, 48, 117-120.

25. Brosseau, L.; Yonge, K. A.; Robinson, V.; Marchand, S.; Judd, M.; Wells, G.; Tugwell, P., Thermotherapy for Treatment of Osteoarthritis. Cochrane Database Syst. Rev. 2003, CD004522.

26. Mannoor, M. S.; Tao, H.; Clayton, J. D.; Sengupta, A.; Kaplan, D. L.; Naik, R. R.; Verma, N.; Omenetto, F. G.; McAlpine, M. C., Graphene-Based Wireless Bacteria Detection on Tooth Enamel. Nat. Commun. 2012, 3, 763.

27. Lorwongtragool, P.; Sowade, E.; Watthanawisuth, N.; Baumann, R. R.; Kerdcharoen, T., A Novel Wearable Electronic Nose for Healthcare Based on Flexible Printed Chemical Sensor Array. Sensors 2014, 14, 19700-19712.

28. Kassal, P.; Kim, J.; Kumar, R.; de Araujo, W. R.; Steinberg, I. M.; Steinberg, M. D.; Wang, J., Smart Bandage with Wireless Connectivity for Uric Acid Biosensing as an Indicator of Wound Status. Electrochem Commun 2015, 56, 6-10.

29. Koh, A.; Kang, D.; Xue, Y.; Lee, S.; Pielak, R. M.; Kim, J.; Hwang, T.; Min, S.; Banks, A.; Bastien, P.; Manco, M. C.; Wang, L.; Ammann, K. R.; Jang, K. I.; Won, P.; Han, S.; Ghaffari, R.; Paik, U.; Slepian, M. J.; Balooch, G.; Huang, Y. G.; Rogers, J. A., A Soft, Wearable Microfluidic Device for the Capture, Storage, and Colorimetric Sensing of Sweat. Sci Trans. Med. 2016, 8, 366ra165.

30. Gao, W.; Emaminejad, S.; Nyein, H. Y. Y.; Challa, S.; Chen, K. V.; Peck, A.; Fahad, H. M.; Ota, H.; Shiraki, H.; Kiriya, D.; Lien, D. H.; Brooks, G. A.; Davis, R. W.; Javey, A., Fully Integrated Wearable Sensor Arrays for Multiplexed in situ Perspiration Analysis. Nature 2016, $529,509-514$.

31. Lee, H.; Choi, T. K.; Lee, Y. B.; Cho, H. R.; Ghaffari, R.; Wang, L.; Choi, H. J.; Chung, T. D.; Lu, N. S.; Hyeon, T.; Choi, S. H.; Kim, D. H., A Graphene-Based Electrochemical Device with Thermoresponsive Microneedles for Diabetes Monitoring and Therapy. Nat. Nanotechnol. 2016, $11,566-572$.

32. Emaminejad, S.; Gao, W.; Wu, E.; Davies, Z. A.; Nyein, H. Y. Y.; Challa, S.; Ryan, S. P.; Fahad, H. M.; Chen, K.; Shahpar, Z.; Talebi, S.; Milla, C.; Javey, A.; Davis, R. W., 
1

2

3

4

5

6

7

8

9

10

11

12

13

14

15

16

17

18

19

20

21

22

23

24

25

26

27

28

29

30

31

32

33

34

35

36

37

38

39

40

41

42

43

44

45

46

47

48

49

50

51

52

53

54

55

56

57

58

59

60
Autonomous Sweat Extraction and Analysis Applied to Cystic Fibrosis and Glucose Monitoring Using a Fully Integrated Wearable Platform. Proc. Natl. Acad. Sci. USA 2017, 114, 4625-4630. 

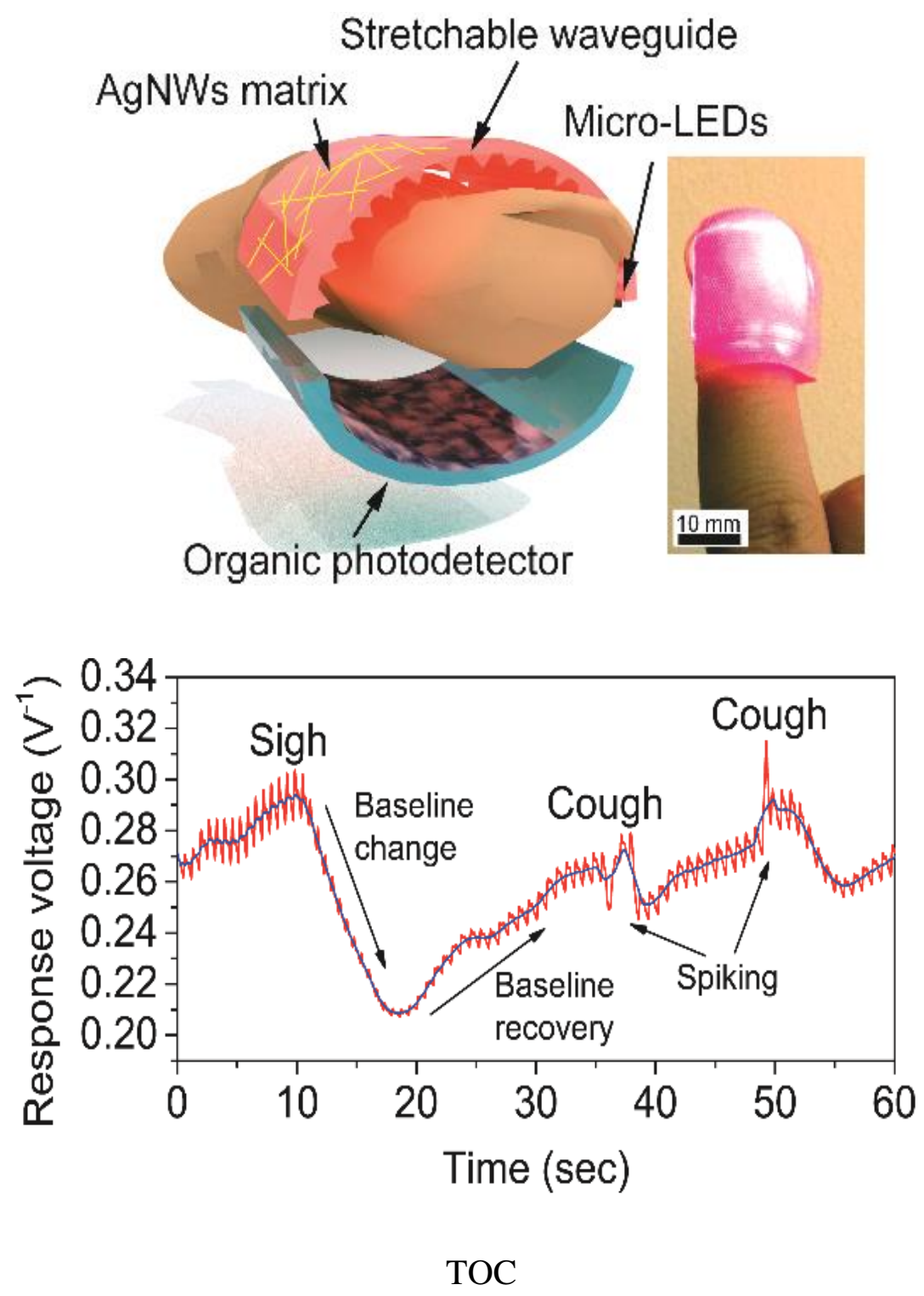